\title{
NUEVOS DOCUMENTOS SOBRE ROJAS ZORRILLA Y SU TEATRO
}

\author{
ABRAHAM MADROÑAL \\ Instituto de la Lengua Española, CSIC
}

\section{RESUMEN}

Se publican una docena de documentos inéditos sobre Rojas Zorrilla referidos a su biografía y a algunas comedias y autos. En buena parte dichos documentos son autógrafos del poeta y añaden o matizan informaciones concretas sobre él y sus obras.

Palabras clave: Documentos inéditos, manuscritos de Rojas Zorrilla, teatro español del Siglo de Oro.

\section{ABSTRACT}

This article contains twelve unpublished documents on Rojas Zorrilla, related to his biography and literary works (comedias and autos sacramentales). The majority are handwritten by the poet himself, and they provide new information relevant to our knowledge of his life and to the understanding of his works.

Key words: Seventieth Century unpublished documents. Rojas Zorrilla manuscripts. Spanish Golden Age Theatre.

Sobre el dramaturgo Francisco de Rojas Zorrilla nos ha quedado poco rastro en documentos, apenas los que integran su expediente en la orden de Santiago y algunas referencias sueltas que tienen que ver con su producción literaria, fundamentalmente datos del estreno, la venta o el pago de alguna obra y la colaboración que el poeta mantuvo en diversas reuniones de ingenios, como las famosas academias burlescas celebradas en Buen Retiro en los años 1637 y 1638. Por eso la aparición de nuevos documentos sobre el poeta y su obra viene hoy a ofrecernos algunos datos que nos permitan matizar o añadir algo a una biografía ya de por sí escasa o sugerir algún aspecto desconocido hasta ahora de la representación de sus obras ${ }^{1}$. Además, al ser buena parte de estos nuevos documentos inéditos autó-

${ }^{1}$ Para no repetir títulos innecesariamente, remito a la «Bibliografía crítica sobre Francisco de Rojas Zorrilla», de Rafael GonZÁleZ CAÑAL, en Felipe PEDRAZA, Rafael González Cañal y José Cano Navarro (eds.), Toledo: entre Calderón y Rojas (Almagro: Universidad de Castilla-La Mancha-Festival de Almagro, 2003, pp. 217-240) y a su versión actualizada en el presente volumen monográfico. 
grafa de Rojas, creemos que su reproducción tiene un valor añadido en el caso de nuestro poeta, en cuyos manuscritos originales de comedias y autos no siempre es fácil distinguir su letra de la de otros colaboradores o copistas. El hecho de reproducir alguno de estos documentos en facsímil puede facilitar la tarea de quienes trabajen con dichos autógrafos de sus obras teatrales.

\section{NUEVOS DOCUMENTOS PARA UNA ESCUETA BIOGRAFÍA}

Poco se ha añadido a la biografía de Francisco de Rojas Zorrilla desde que publicara Cotarelo su ensayo biobibliográfico dedicado al poeta hace casi cien años ${ }^{2}$. El que fuera secretario de la Española tuvo la fortuna -y el tesón- de localizar algunos documentos como la partida de defunción del poeta y testamentos de varios familiares que aclararon mucho los hechos vitales del creador de Entre bobos anda el juego. Dichos datos se han venido repitiendo una y otra vez, apenas sin modificación, por los estudiosos y editores de Rojas hasta nuestros días.

Ahora bien, la base de la biografía de Rojas en realidad se debe al descubrimiento que don José Antonio Álvarez y Baena hizo de una parte del expediente de las pruebas de ingreso del poeta en la Orden de Santiago, que se encuentra en el Archivo Histórico Nacional (y que el fechó en 1641), gracias al cual desechó a Rojas como hijo de Madrid, contra el testimonio de Pérez de Montalbán, y apuntó su abolengo toledano ${ }^{3}$. Cotarelo juzgó que fue error de Baena dar ese año, pero como veremos el error lo cometió él propio don Emilio, por cuanto Baena tuvo acceso al expedientillo de las pruebas, en efecto de $1641^{4}$; mientras los eruditos posteriores, y también Cotarelo, solo al expediente como tal, que abarca desde los años 1643 a 1646. Dichas pruebas en su conjunto incluyen buen número de documentos entre los que se encontraba (hoy ya no está) la partida de bautismo del dramaturgo, que publicó por primera vez Hartzenbusch en $1860^{5}$. También la publicaron después otros eruditos como el mencionado Cotarelo o Cayetano Alberto de La Barrera. La información que nos dieron todos ellos, pero en especial el biógrafo por antonomasia de Rojas Zorrilla citado al

${ }^{2}$ Emilio Cotarelo, Don Francisco de Rojas Zorrilla. Noticias biográficas y bibliográficas. Madrid: Revista Archivos, 1911. Cito por la edición facsímil, Toledo: Real Academia de Bellas Artes y Ciencias Históricas, 2007 (en curso de publicación).

3 Joseph Antonio Álvarez y BAEnA, Hijos de Madrid, ilustres en santidad, dignidades, armas, ciencias y artes. Madrid: Oficina de D. Benito Cano, 1791, IV, p. 407. Baena desdice a los que como Montalbán opinaban que era natural de Madrid o, como García de la Huerta, a los que le creían natural de San Esteban de Gormaz (siguiendo a Nicolás Antonio). Da cuenta también de sus verdaderos padres.

${ }^{4}$ Op. cit., p. 6.

${ }^{5}$ Lope DE VeGA, Comedias escogidas, IV. Madrid, 1860 (BAE, LII), p. viii. 
principio, permite resumir básicamente la cronología conocida de Rojas, con referencia documental detrás, de la siguiente forma:

Nace en Toledo el 4 de octubre de 1607 y se bautiza en la parroquia de San Salvador el 27 del mismo mes. Entre los años de 1609 y 1616 sabemos poco: en 1609 nace su hermano Diego, un año más tarde se traslada la familia a Madrid; en 1611 nace su hermana Luisa Ana y en años sucesivos, a razón de uno por año, su hermana Bernarda y su hermano José; un poco más tarde, en 1616 nace su hermana Manuela María. En 1623 tiene lugar un suceso importante: muere su tío y protector Diego Lucio Zorrilla, hermano de la madre del poeta.

No tenemos más datos hasta 1631, en que colabora en el Anfiteatro de Felipe el Grande de Pellicer y Tovar. Ese mismo año se casa su hermana Bernarda. En 1632 lo cita en el Para todos Montalbán como autor de ingeniosas comedias, y por fin en 1633, el 23 de febrero estrena su primera obra, Persiles y Segismunda en El Pardo ante los Reyes (compañía de López de Sustaete). Ese mismo año escribe Los tres blasones de España con Antonio Coello. El 9 de diciembre de 1634 termina Peligrar en los remedios (para Roque Figueroa) y representa El primer marqués de Astorga.

El año de 1635 se puede decir que es especialmente próspero para el dramaturgo, por cuanto representa Peligrar en los remedios (Roque de Figueroa) y No hay ser padre siendo rey y El catalán Serrallonga, esta última en colaboración (todas representadas por Prado); El desafío de Carlos $V$ (Avendaño), El profeta falso, Mahoma y el villano gran señor y Santa Isabel, reina de Portugal (Martínez de los Ríos). Un año después, en 1636, representa ante los reyes Progne y Filomena, El jardín de Falerina con Calderón y El mejor amigo el muerto, con este y Belmonte, Obligados y ofendidos (todas Juan Martínez) y No hay amigo para amigo (Pedro de la Rosa). Y aunque escrita antes, se representa Casarse por vengarse. Colabora también en la Fama póstuma, de Lope.

En 1637 participa en la Academia burlesca de Buen Retiro por la venida de la princesa de Cariñán y un año más tarde en el mismo lugar en otra academia burlesca, ahora por la venida de la duquesa de Chevreuse. Justamente en 1638 los avisos de la corte difunden rumores sobre la muerte violenta del poeta, pero pocos días después se rectifica la noticia. Quien sí fallece ese año es su padre. En 1639 se aprueban de la primera parte de sus comedias y Rojas empieza a escribir autos para el Corpus, como el Hércules. El 11 febrero termina la comedia Nuestra Señora de Atocha (la representa Antonio de Rueda). Colabora en las Lágrimas panegíricas de Montalbán.

El 4 de febrero de 1640 se inaugura el Coliseo del Buen Retiro con Los bandos de Verona y el 7 de junio se estrenan en el Corpus sus autos El rico avariento y Las ferias de Madrid (que representa Bartolomé Romero). Por su parte, en el plano personal tiene lugar el matrimonio con doña Catalina Yáñez Trillo de Mendoza (el 21 de noviembre). Publica este 
año la primera parte de sus comedias y estrena Abrir el ojo. El 21 de enero del año siguiente tienen lugar las velaciones con su esposa. Escribe dos autos para la fiesta del Corpus: El Sotillo de Madrid (que representan los actores Jusepe y la Negrilla) y Sansón (en este caso para la autora llamada la Viuda, con los actores Íñigo de Loaísa y Jusepa) y el 8 de julio firma obligación de pago al doctor Pedro López de Cuéllar de 800 reales de plata. El 25 de junio de 1642 nace su hijo Antonio Juan.

Según Cotarelo, un año después, en 1643 tiene lugar la propuesta de concesión del hábito por parte de Felipe IV, y en 20 de agosto el Consejo de Órdenes nombra informantes para las pruebas. En 1644 reclama al Consejo que se continúe el expediente de pruebas, justo cuando obtiene privilegio para imprimir su segunda parte de comedias. En 1645 publica la segunda parte de comedias y el 13 de octubre el Consejo de Órdenes considera probado que su padre fue escribano en Murcia. Obtiene la dispensa papal por haber ejercido su padre como escribano y el hábito de Santiago. El 16 de mayo de 1646 testifica sobre la muerte de José Calderón de la Barca, hermano del dramaturgo. Muere en Madrid el 23 de enero de 1648.

Como se ve, también la biografía de Rojas se puede calificar como la de Calderón, «la biografía del silencio», hasta el punto de que — como decía Cotarelo- si Felipe IV no le hubiese honrado con el hábito de Santiago, no se sabría apenas nada de su origen, familia, etc. Aun así, las noticias son muy escasas, pero creemos que no se han aprovechado siquiera convenientemente, de manera que nos podemos permitir añadir alguna cosa más a lo ya conocido.

En efecto, hoy se pueden aportar algunos datos nuevos a la vista de la documentación encontrada en el Archivo Histórico Nacional, particularmente en los expedientillos de la orden militar de Santiago. Estos nuevos datos no dejan de tener interés porque rectifican otros ya sabidos y aportan, pensamos, algunas noticias que son de interés para el conocimiento de la peripecia vital de Rojas.

En primer lugar la fecha de concesión del hábito de Santiago por parte del rey Felipe IV no es 1643, como se ha escrito, sino primeros de marzo de 1641. Ya La Barrera, citando a Álvarez y Baena, apuntaba justamente hacia ese año, pero ninguno de los biógrafos posteriores, incluyendo al benemérito Cotarelo, lo tuvo en cuenta, con lo que la fecha de 1643 se ha venido repitiendo en estudios y ediciones del poeta.

Además, muy probablemente la causa de que se le concediera el hábito no fue una merced real; sino que en última instancia al menos la propició el matrimonio de Rojas y doña Catalina, que quizá se llevó a cabo (entre otras cosas) para obtenerlo precisamente, dado que en un apunte manuscrito del documento n. 9 encontramos que quien se casara con la tal doña Catalina tenía derecho a obtener un hábito y que la junta (y no el Rey) había decidido que fuese de Santiago. 
Es posible que Felipe IV estuviera agradecido al dramaturgo, bien porque le deleitaran sus comedias representadas en la corte o en los sitios reales, bien porque agradeciera los buenos servicios que había prestado en las academias burlescas celebradas en Buen Retiro en 1637 y 1638, en las que sabemos que la predilección de la reina señaló al poeta toledano para encargarse de desempeñar ciertos cargos y de dar los vejámenes correspondientes. Quizá también como compensación por haber sido herido de gravedad con motivo de uno de esos vejámenes en la segunda de las academias citadas. Pero todo ello, por lo menos en lo que se refiere a la concesión del hábito, ha de quedar de momento en el terreno de la suposición.

En segundo lugar, según los datos de Cotarelo, Rojas se habría visto favorecido por un supuesto amigo como Quevedo, quien habría actuado en su proceso. La cita concreta del estudio de Cotarelo dice así:

En virtud de esto, el Consejo mandó continuar la información, y nombró para que hiciese oficios de escribano de cámara de la Orden en ellas a D. Francisco de Quevedo, del mismo hábito, vuelto a la corte después de su larga prisión en San Marcos ${ }^{6}$.

Es verdad que no se dice nada las simpatías del autor del Buscón, pero prácticamente se induce al lector a pensar en razones de camaradería literaria, que seguramente nunca existieron entre los dos autores ${ }^{7}$. Pero la realidad está todavía más lejos de lo que nos sugiere el erudito académico: el Francisco de Quevedo que firma el documento no es don Francisco de Quevedo y Villegas, por cuanto el firmante hace oficio de escribano de cámara del Consejo de la Órdenes por lo menos desde 1641, según otros documentos consultados, cuando el verdadero Quevedo estaba preso y no podía ejercer como tal. Por otra parte este Francisco de Quevedo, escribano, nunca firma con los apellidos del poeta ni con el tratamiento de don que este tenía y del que hacía gala siempre, como es natural. Por si fuera poco, ni la letra ni la rúbrica de su firma coinciden con la que conocemos del auténtico Quevedo. Hay que borrar, pues, de la biografía de Rojas el nombre de Quevedo, que no es probable que fuera amigo del poeta y que desde luego no intervino en la concesión de su hábito.

Por otra parte, consta la testificación de peso de personas de calidad como el conde de Mora o el marqués de Malpica a favor del poeta (o, por

${ }^{6}$ Don Francisco de Rojas Zorrilla, cit., p. 83.

${ }^{7}$ Quevedo estaría mucho más cerca sin duda de la opinión de su amigo, este sí verdadero y comprobado, Bartolomé Jiménez Patón, el cual escribe a las alturas de 1638: «De cuatro años a esta parte parece que algunos descendientes de moros y de judíos y de luteranos y de otra seta nuevamente convertidos han aspirado a pretender y aún atrevídose a intentar que los reciban en las comunidades de colegios, religiones, iglesias y familias que por leyes de los Reyes Católicos de España y bulas de los sumos pontífices romanos les está prohibido». (B. JimÉnEZ PATÓN, Discurso a favor del santo y loable estatuto de la limpieza. Granada: Andrés de Santiago Palomino, 1638, f. 1). 
lo menos, no en contra), en 1645; ambos dicen que lo conocen, el primero de cinco años a esta parte, el segundo desde hace poco tiempo; pero que no conocen nada de sus familia; es verdad que también mencionan que no han oído cosa alguna en contra de su procedencia hidalga.

Es cierto que en el proceso encontramos igualmente el testimonio de amigos que conocen a Rojas como dramaturgo, es el caso de Blas Fernández de Mesa ${ }^{8}$, contador mayor de la ciudad de Toledo, que era igualmente autor dramático y que debía de querer bien al poeta, con quien había tomado parte en las famas póstumas de Lope y Montalbán. Por fuerza le conocía como autor de comedias y autos, ya que compartía escenario en las representaciones del corpus toledano. El caso es que testifica a su favor, aunque cuenta un curioso episodio relacionado con el famoso «Moro», pariente de Rojas; según Fernández de Mesa era hombre de malas costumbres, algo adusto, carecía de barba y además era zurdo, por si fuera poco era altivo y soberbio, hasta tal punto de que en un viaje que tuvo que hacer con este testigo, le abandonó por el hecho de no sentarle a su mesa a comer. Otro de estos testigos favorables sin duda relacionados con Rojas por el teatro en Toledo es Alberto de la Palma Hurtado, regidor de la ciudad, que se ocupa de disponer las representaciones del corpus toledano de 1640 y quien recibe de puño y letra de Calderón una carta, con la que le envía una loa y le promete el envío del auto Psiquis y Cupido. Se ve que la ciudad había comisionado a de la Palma para que apremiara al dramaturgo ${ }^{9}$.

Pero también aparecen enemigos, como el testigo Francisco Francés de Úbeda, quien declara en 1645 que el intento de Rojas de presentarse como originario de San Esteban de Gormaz es una falsificación y una mentira del pretendiente; en su lugar señala el origen toledano de la familia y la ascendencia judía, hasta el punto de que algunos parientes habían sido quemados por la Inquisición y tenían sambenito colgado en iglesias toledanas. Otros señalan a un pariente morisco, alquilador de mulas o carpintero. Por si fuera poco, advierta a su Alteza que no nombre como instructores a personas como don Fernando de Peralta, que tienen tan poco celo con la honra de la orden y no se demora en examinar testigos, cosa que sí hizo

${ }^{8}$ Autor de comedias, autos, loas y algunos entremeses, como el titulado Las tajadas. La Barrera le atribuye las comedias Los Silvas y Ayalas, Cada uno con su igual y la que cito inmediatamente. Véanse las modernas ediciones de su comedia La fundadora de la Santa Concepción: comedia en dos partes con estudio introductorio de Nancy K. Mayberry (Nueva York: Peter Lang, 1996) y el padre Luis Vázquez (Madrid, 1997). Fernández de Mesa escribe también un auto y una loa para representar en el corpus toledano, para lo cual presenta una «memoria de apariencias». Véase Fernando MARTínEZ GIL, Mariano GARcía RuIPÉREZ y Francisco CROSAS, «Calderón de la Barca y el Corpus toledano de 1640: recuperación de una carta autógrafa en el Archivo Municipal de Toledo», en Criticón, 91, 2004, pp. 93-120, en especial pp. 112-114.

${ }^{9}$ Cfr. el artículo cit. «Calderón de la Barca y el Corpus toledano de 1640», pp. $110-112$. 
este Francés de Úbeda, pues a su testimonio añade la lista de las personas que opinan como él del falso linaje del pretendiente.

Rojas había hecho el intento de emparentar con personas nobles o hidalgas, en particular con los Chiriboga y otros Rojas y Zorrilla, de noble origen, pero algunos testigos lo rechazan, aunque otros - seguramente amigos - lo defienden a capa y espada. Es indudable que le poeta mismo estuvo en Toledo visitando a diferentes personas con el ánimo de señalar parentescos, quizá inexistentes, y para enseñar un memorial que sugería lo que tenían que declarar. Los 800 reales de plata que pide prestados Rojas en 1641, como arriba se expresa, tal vez tuvieran la intención de refrescar la memoria de algún «pariente» noble y lejano. Se buscaron amigos en todos lados, incluso se pidió que declarase el sacerdote que le había bautizado, el ya anciano doctor Eugenio de Andrada, cura de San Salvador, quien testifica que conoce a «don Francisco de Rojas Zorrilla, pretendiente, a quien este testigo bautizó en dicha parroquia» y que sus padres «fueron y son hijosdalgo [...] y limpios cristianos viejos» ${ }^{10}$. También desdice lo de su antepasado el Moro. Hoy nos parece demasiado favorable a Rojas para ser ecuánime.

Con esa misma pretensión de apuntar la nobleza de su abolengo, alguna vez esgrimió los servicios militares de su padre, el alférez Rojas, para borrar ese pasado como escribano de número en la ciudad de Murcia ${ }^{11}$. Pero el poeta firmó siempre con el tratamiento de «don», señalando así una procedencia noble. Bien advierte otro toledano Rojas, este noble sin duda ninguna y experto en genealogías e historia, el conde de Mora, cuando le preguntan sobre la posible nobleza de Rojas Zorrilla, que «en esta corte $[\ldots]$ no se puede distinguir la noblesa que tenga cada uno en los que no son señores o titulados». Y añade que él «no hase concepto de lo que se dice de las calidades, mientras dura la pretención, porque todos hablan por malo o buen afecto» ${ }^{12}$. Puede ser un buen resumen de estas pruebas de nobleza.

Nos queda claro hoy que el nombramiento del doctor González Álamo fue un impedimento importante para Rojas en la consecución del hábito: este sacerdote se muestra opuesto al papel complaciente de su compañero en la tarea, el caballero santiaguista don Fernando de Peralta y Velasco,

${ }_{10}$ Expediente de pruebas de la Orden de Santiago, AHN 7202, ff. 59vº-60.

11 Sus diferentes hojas de servicio se pueden consultar también hoy en el expediente de Santiago, seguramente las aportó el propio dramaturgo para demostrar las calidades de su padre. En realidad, dan cuenta de los diferentes cometidos como soldado raso primero, después aventajado y por último como alférez en distintos lugares.

12 AHN, Órdenes Militares, pruebas de Santiago de Rojas Zorrilla, el documento lleva fecha de 12 de octubre de 1645, s. f. El Conde de Mora, don Pedro de Rojas y Niño, fue autor de unos Discursos ilustres, históricos y genealógicos (1636) y de una Historia de la imperial...ciudad Toledo (1653-1654). 
del cual dice que tiene poco interés en saber la verdad ${ }^{13}$. Por el contrario, él presenta un buen número de testigos que declaran que las pruebas que aporta Rojas son falsas y que muchas voces de Toledo saben que procede de moriscos y judaizantes quemados por la Inquisición. Por eso, el hecho de que este doctor se excusara y que el 24 de septiembre de 1644 se nombrase al licenciado Sebastián Becerra Nieto, también religioso de la misma orden, sin duda allanó el camino de quienes querían ver lucir al pretendiente la roja insignia de Santiago.

De hecho, lo que queda de todo ello es algo contradictorio: algunos testigos apuntan hacia un pasado poco claro, pero no todos coinciden. A Felipe IV le llegó un informe-resumen que decía que en el poeta concurrían las calidades exigidas para ser nombrado caballero de Santiago, con la excepción del oficio de escribano del padre, para el que se pidió la dispensación papal (que hoy obra también en el expediente). Sin duda, el interés particular del monarca allanó las dificultades, él mismo rubrica de su mano varios de los documentos mencionados. De tal forma que, cinco años después de empezado el proceso (y parece un plazo excesivamente largo), exactamente el 16 de marzo de 1646, obtiene la deseada prebenda.

Lo que sí parece seguro a tenor del expediente consultado es que Rojas no estudió en la universidad de su ciudad natal, porque si así lo hubiera hecho es seguro que habría utilizado a alguno de sus compañeros toledanos de facultad para testificar a su favor en dicho proceso. Ninguno de los testimonios consultados hace valer esa camaradería con el poeta. Lo más probable es que haya que seguir buscando en los archivos universitarios de Alcalá y Salamanca, hasta dar con el dato preciso de su matrícula en alguna de las facultades que en su tiempo existían.

\section{NuEVOS DOCUMENTOS SOBRE SU TEATRO}

Nos quedan también muy pocos documentos sobre la actividad dramática de Rojas. Ya hace bastantes años ese benemérito investigador de archivos y bibliotecas que fue don Cristóbal Pérez Pastor consiguió encontrar datos de buen número de escritores áureos, entre los que también se encontraba Rojas. Por el documento publicado, sabemos que en el año cómico de 1633 a 1634 se le pagan 900 reales a Rojas por una comedia escrita en colaboración con su amigo don Antonio Coello ${ }^{14}$. Shergold y Varey recogieron también importantes referencias documentales, referidas sobre todo a la representación de algunos autos de Rojas ${ }^{15}$.

${ }^{13}$ Así lo dice en una declaración que hace el tal doctor Álamo con fecha de 11 de octubre de 1644. Órdenes militares, Santiago. Expediente, signatura 7202.

${ }^{14}$ Memorias de la Real Academia Española, X, p. 111.

15 N. D. Shergold-J. E. VAREY, Los autos sacramentales en Madrid en la época de Calderón. 1637-1681. Madrid: Clavileño, 1961, p. 28. 
Más recientemente se han localizado otros documentos importantes, como uno que afecta a ocho comedias suyas (algunas solo parcialmente) que el mismo dramaturgo vende en 21 de marzo de 1635 al librero Diego Logroño para que «las pueda imprimir y venderlas». Entendemos que como impresos sueltos, pero no tenemos seguridad de tal $\operatorname{cosa}^{16}$. Precisamente Diego Logroño es quien hace imprimir en ese año la Veinte y una parte verdadera de las Comedias del fénix de España, del maestro Lope (Madrid: Viuda de Alonso Martín, 1635).

Todavía podemos dar cuenta de la existencia de otros testimonios documentales interesantes, como por ejemplo el que se encuentra en el manuscrito autógrafo de la comedia Peligrar en los remedios, que Rojas escribió para Roque de Figueroa en diciembre de 1634, con el objeto de que la representara el año siguiente. Dicho manuscrito, de puño y letra del poeta que estampa también su firma al final, contiene unas interesantes indicaciones dirigidas al cómico, en las que le da instrucciones sobre la representación de la obra y la importancia de los papeles que se dan en ella. Desde luego da cuenta de la cercanía que tenía Rojas Zorrilla con los cómicos que representaban sus comedias, los cuales debían de pedirle textos escritos ex profeso para ellos.

Hoy podemos añadir a estos documentos uno más, localizado en el archivo del Ayuntamiento de Toledo y de un interés extraordinario. Se trata de una memoria de apariencias de 1645 escrita por el propio Rojas, que afecta a dos autos representados en la ciudad natal del dramaturgo: La viña de Nabot y Galán, discreto y valiente, que a partir de ahora tiene sus fechas ad quem en los documentos que reproducimos ${ }^{17}$. Es un documento excepcional, porque se trata de un autógrafo del poeta cuyo carácter de tal hasta ahora se desconocía, que además añade un dibujo de su propia mano, con objeto de facilitar el trabajo a los que tuvieran que disponer el teatro. Aunque carece de fecha, es fácil localizarlo en 1645.

Sabemos por la documentación consultada en dicho archivo que el autor de comedias que se ocupó de los autos de ese año fue precisamente Pedro Ascanio, dado que aparece un documento firmado por él el 7 de mayo de 1645 (aunque escrito por la mano del escribano del ayuntamiento) en el que se obliga a hacer dos autos, dos entremeses, dos bailes, dos loas y un sarao en dicha fiesta del Corpus ${ }^{18}$, pero también en otras partes de la ciu-

${ }^{16}$ Alejandro Rubio SAN ROMÁN y Elena MARTínez CARRO, «Aportación documental a la obra de Rojas Zorrilla», en Dicenda, 24, 2006, pp. 219-234, con reproducción facsímil del documento, en que se aprecia la firma de Rojas.

${ }^{17}$ He dado cuenta del descubrimiento en el trabajo «Autos de Rojas Zorrilla en el Corpus toledano de 1645», en Francisco de Rojas. Escenario y vida de un autor toledano. Toledo: Teatro Rojas, 2007.

18 Archivo Municipal de Toledo. Fondo histórico, caja 881. Para mayor información sobre la celebración de la fiesta en Toledo es útil el libro de Hilario Rodríguez de Gracia, El Corpus en Toledo. Fiesta religiosa y profana en los siglos XVI y XVII. Toledo: Caja de Castilla La Mancha, 2001. 
dad. Así pues, fue Ascanio el que representó en Toledo los autos de Rojas Zorrilla y el documento nos da además curiosas noticias sobre la manera de proceder en las representaciones del Corpus toledano ${ }^{19}$.

Parte del documento de Rojas que mencionamos del Archivo Municipal de Toledo estaba bien localizada en un trabajo reciente ${ }^{20}$, que sin embargo señala que nuestro documento no es autógrafo y apunta a Mira de Amescua como autor de la comedia Galán, valiente y discreto. Pero no cabe duda de que el documento se refiere a dos autos, el casi homónimo de Rojas Galán, discreto y valiente ${ }^{21}$ y el también suyo titulado La viña de Nabot, como tampoco la hay en que el documento citado sea autógrafo de este dramaturgo. En efecto, ambos autos son de nuestro poeta y no están afectados por problemas de atribución que sí atañen a otros de la misma época, como por ejemplo el que escribió Calderón también para el corpus toledano de 1644, que lleva por título La humildad coronada y que se atribuyó precisamente a Rojas en la impresión que se hizo del mismo con el título de Los árboles en la recopilación Autos sacramentales al nacimiento de Cristo, de 1675. En el caso de los dos autos auténticos de Rojas enseguida se aprecia que la memoria de apariencias escrita por este corresponde exactamente a las circunstancias de la representación de la obra que se recogen en los manuscritos o la impresión de dichos autos.

Se trata de un pequeño documento de dos hojas, la primera escrita por las dos caras (a razón de una memoria de apariencias por auto) y la segunda utilizada solo en la primera cara, en la cual consta un dibujo también de la propia mano del dramaturgo, que representa la disposición del escenario donde tendría lugar el auto segundo, Galán, discreto y valiente. Están escritas con la caligrafía vacilante del poeta, no con esa otra más cuidada y propia de las copias en limpio de sus obras dramáticas, como por ejemplo, el manuscrito autógrafo de su comedia Peligrar en los remedios, que se conserva hoy en la Biblioteca Nacional ${ }^{22}$.

${ }^{19}$ La tesis de Isabel SÁnCHEZ-PALEnCIA MANCEBO, Fiesta y literatura en Toledo durante el siglo XVII. Madrid: Universidad Complutense, 1992 (4 vols.), da cuenta de esta documentación del Archivo Municipal y se detiene en el documento firmado por Ascanio (tomo I, p. 158-160), pero no menciona la memoria de apariencias de Rojas de que hablo inmediatamente.

${ }^{20}$ El citado «Calderón de la Barca y el Corpus toledano de $1640 \ldots »$, donde se dice: «Del mismo autor toledano [Rojas Zorrilla] es La viña de Nabot, que posiblemente se representó en el Corpus de 1645 y cuya memoria de apariencias, no autógrafa, también se ha conservado. Asimismo contamos con las apariencias de Galán, discreto y valiente, a buen seguro la escrita por Antonio Mira de Amescua» (p. 107).

${ }^{21}$ Nótese que cuando el auto se imprime en la recopilación Autos sacramentales (Madrid: Antonio Francisco de Zafra, 1675) lleva precisamente este título (f. 1), aunque en el índice de este libro figure Galán, valiente y discreto, seguramente puesto por mano ajena.

${ }_{22}$ Signatura Ms. Vitrinas. 7-6. Agradezco a mi amigo Rafael González Cañal las facilidades para consultar este y otros autógrafos. 
Sin duda, se trata de la propia mano del dramaturgo, como es fácil observar si cotejamos el documento con otros dos de su letra y de la misma o parecida fecha (1644 y 1645) que se conservan hoy en el Archivo Histórico Nacional, en el citado expediente de pruebas para conseguir el título de caballero de la orden de Santiago y que en parte reproducimos aquí. Por si fuera poco y quizá ante el temor de que los oficiales en cuestión no entendieran la letra del autor, el escribano del Ayuntamiento vuelve a copiar el documento de Rojas y afortunadamente la copia se nos ha transmitido hoy (en papel sellado también de 1645) junto con su original.

Precisamente el auto La viña de Nabot se conserva en dos manuscritos de la Biblioteca Nacional, uno con la signatura 17398, donde se indica que fue copiado en 1648 para la fiesta del Corpus de Granada, y otro con la signatura 15585, copiado sin duda para el corpus toledano. Ninguno de los dos manuscritos es copia del otro, como ya indicó Américo Castro ${ }^{23}$, sino que proceden de un original perdido, quizá el que Rojas había mandado a Toledo. Se da la circunstancia de que el autor o - más probablementequien representase el auto, adecua la alusión final al lugar de representación, y así lo que en el manuscrito que copia el texto de la representación toledana es «corona de las ziudades, / gran Toledo» se transforma en el que copia el auto para Granada, y un tanto cacofónicamente, en «corona de las çiudades, / gran Granada» ${ }^{24}$.

\section{EDICIÓN}

Publico a continuación trece documentos de Rojas, una buena parte de los cuales es autógrafa e inédita. Solo uno de los que edito ahora fue publicado ya por Cotarelo, pero también en este caso doy la transcripción y corrijo algunos errores, además aporto la reproducción facsímil del documento que me ha servido para considerar como autógrafa la memoria de apariencias localizada en el archivo del Ayuntamiento de Toledo.

En cuanto a la edición en sí, me he permitido modernizar la grafía según el uso actual, es decir, actualizando lo que no tiene valor fonológico, y desarrollar abreviaturas evidentes.

${ }^{23}$ En su edición del auto junto con la comedia Cada cual lo que le toca. Madrid: Centro de Estudios Históricos, 1917, pp. 250-251.

${ }^{24}$ Ibíd. Aprovecho para agradecer la ayuda de Mariano García Ruipérez (Archivo Municipal de Toledo) y de Elvira Fernández del Pozo (Archivo Histórico Nacional). 


\section{APÉNDICE DOCUMENTAL}

\section{1. [8 de marzo de 1641. Felipe IV hace merced del hábito de Santiago a don Francisco de Rojas Zorrilla.]}

[Papel del sello cuarto.1641]

El Rey.

Presidente y los del mi Consejo de las órdenes de Santiago, Calatrava y Alcántara, cuya administración yo tengo por autoridad apostólica. A don Francisco de Rojas Zorrilla he hecho merced, como por la presente se lo hago, del hábito de la orden de Santiago. Yo os mando que, presentándoseos esta mi cédula dentro de treinta días contados desde el del a fecha della, proveáis que se reciba la información que se acostumbra para saber si concurren en él las calidades que se requieren para tenerle conforme a los establecimientos de la dicha orden de Santiago, y pareciendo por ella que las tiene, le libréis título del dicho hábito para que yo le firme, que así es mi voluntad, y que des[de el desp]acho se tome la razón en mis libros de registro y demás dentro de cuatro meses, y no lo haciendo así, no se use desta ni ese Consejo le ejecute.

Fecha en Madrid, a ocho de marzo de mil y seiscientos y cuarenta y un años. Yo el Rey

Por mandado de nuestro señor Jerónimo de Villanueva.

(AHN, Órdenes militares. Santiago. Expedientillo, signatura 2409, doc. n. ${ }^{\circ}$ ).

2. [4 de noviembre de 1642. Don Francisco de Rojas Zorrilla presenta cuatro fiadores, que son su cuñados, el hermano de su mujer, don Eugenio Yáñez de Mendoza, regidor de Guadalajara, y el marido de su hermana, Francisco Gómez Doyagüe; don Andrés Ferrer y Martín de Salazar. Todos hipotecan sus bienes para atender a las deudas y obligaciones futuras del pretendiente].

(AHN, Órdenes militares. Santiago. Expedientillo, signatura 2409, doc. n. ${ }^{\circ} 3$ )

\section{3. [4 de julio de 1643. Petición de don Francisco de Rojas Zorrilla. Autó-} grafo.]

[Papel del sello cuarto.1639]

Señor:

Don Francisco de Rojas Zorrilla dice que tiene hecha merced de un hábito de la orden del señor Santiago y ha venido presentando la real cédula. Los de vuestro Consejo le mandaron depositar ciento y cincuenta ducados de plata doble y que diese fiador, y habiendo hecho el depósito y estando otorgada ya la fianza con cuatro fiadores que han hipotecado raíces ante Francisco Quevedo, vuestro escribano, don Gregorio de Tapia no se satisface de dicha fianza, antes pide se traiga nuevo fiador. A V. A. pido mande que en virtud della, pues está otorgada en toda forma, se mande despachar informantes. Pues es justicia que pido.

Don Francisco de Rojas Zorrilla [firma y rúbrica]

(AHN, Órdenes militares. Santiago. Expedientillo, signatura 2409, doc. n. ${ }^{\circ}$ ) 


\section{4. [1643. Petición de don Francisco de Rojas Zorrilla. Autógrafo.]}

M. P. Señor:

Don Francisco de Rojas Zorrilla digo que V. Alteza aprobó la fianza que otorgaron cuatro fiadores, mandando que el secretario don Gregorio de Tapia la advirtiese, el cual ha suplicado del auto proveído por los de vuestro Consejo a V. A. Pido que, sin embargo, corra dicha fianza. Pido justicia.

Don Francisco de Rojas Zorrilla [firmado y rubricado]

[Nota. El 13 de agosto de 1643 el licenciado Gregorio Silvestre de Salazar declara que don Francisco de Rojas Zorrilla ha cumplido con la fianza que dio].

(AHN, Órdenes militares. Santiago. Expedientillo, signatura 2409, doc. n. ${ }^{\circ}$ ).

\section{5. [1644. Petición de don Francisco de Rojas Zorrilla. Autógrafo.] ${ }^{25}$}

[Papel del sello cuarto. 1644]

M. P. S.

Don Francisco de Rojas Zorrilla digo que por mandado de Vuestra Alteza se le despacharon por informantes para el hábito de el señor Santiago, de que Su Majestad le hizo merced, a don Fernando de Peralta y al doctor don Sebastián González del Álamo. Y habrá cerca de un año que empezaron sus pruebas en la ciudad de Toledo, y sin haberlas acabado cesaron en continuar las diligencias necesarias, y aunque he acudido a que las prosigan, no lo hacen; antes el dicho doctor Álamo dice se ha escusado y que está ocupado en la cura de el Hospital de donde es administrador, y que no puede ir a Montañas de Espinosa y otras partes donde tengo los orígenes. A V. A. suplico mande a dichos don Fernando de Peralta y doctor Álamo prosigan las pruebas, y de no hacerlo, den escusa por escrito para que V. A. provea lo que fuere servido. Pido justicia.

Don Francisco de Rojas Zorrilla [firmado y rubricado]

(AHN. Órdenes militares. Santiago, expediente 7202).

\section{6. [7 de septiembre de 1644. Francisco de Quevedo, escribano de cámara, da cuenta del nombramiento del licenciado Becerra Nieto en sustitución del doctor Álamo.]}

[Papel del sello cuarto. 1644].

Francisco de Quevedo, que hago oficio de escribano de cámara del Consejo real de las Órdenes en lo tocante a la de Santiago, certifico que habiéndose nombrado a don Fernando de Peralta y al doctor don Sebastián González del Álamo, caballero religioso de la dicha orden de Santiago, para que hiciesen las pruebas del hábito de la misma orden que pretende don Francisco de Rojas Zorrilla, habiendo comenzado las dichas pruebas, el dicho doctor don Sebastián González del Álamo se escusó de las dichas pruebas y acabarlas, y habiéndose visto la escusa por los señores del dicho consejo, se admitió, y en su lugar nombraron al licenciado Sebastián Becerra Nieto, religioso de la dicha orden, cura de la villa de los Santos, para que en compañía del dicho don Fernando de Peralta prosiga y acabe

${ }^{25}$ Lo publica Cotarelo, op. cit., pp. 82-83. Corrijo su transcripción. 
las dichas pruebas desde el estado en que están de la misma forma y manera que lo podía hacer el dicho doctor don Sebastián González del Álamo, en virtud de la comisión y despachos que están dados, que en todo se han de entender con el dicho licenciado Becerra, como si con él hablaran, fueran dirigidos que en caso necesario ceden poder de misión en forma como parece del auto sobre ello proveído que queda en este oficio a que remito. Y porque dello conste, doy la presente en Madrid, a siete de setiembre de mil y seiscientos y cuarenta y cuatro años.

Francisco de Quevedo [firmado y rubricado]

(AHN, Órdenes militares. Santiago. Expediente, signatura 7202).

\section{7. [6 de setiembre de 1645. Petición de don Francisco de Rojas Zorrilla. Autógrafo.]}

Presentado con los papeles en 6 de setiembre de 1645.

M. P. S.

Don Francisco de Rojas Zorrilla dice que a su noticia ha llegado que su padre, Francisco Pérez de Rojas, compró un oficio de escribano del número de la ciudad de Murcia, cuyo título original presenta. Y porque el dicho su padre sirvió a su majestad once años de soldado y alférez de la Armada Real, cuyos servicios presenta, y ansimismo por los servicios del capitán don Diego de Rojas, su hermano, gobernador del fuerte de San Felipe, en Flandes, donde hoy sirve, habiendo diez y ocho años que los continúa en Italia y Flandes, y por los suyos, en virtud de que se le hizo merced del hábito del señor Santiago, suplica a V. A. le despache dicho hábito en la forma que V. A. fuere servido.

Don Francisco de Rojas [firmado y rubricado]

(AHN, Órdenes militares. Santiago. Expediente, signatura 7202).

\section{8. [16 de marzo de 1646. Se despacha título de caballero de Santiago a don Francisco de Rojas Zorrilla.]}

Despacha título de caballero de la orden de Santiago a don Francisco de Rojas Zorrilla, natural de la ciudad de Toledo, inserto en él la dispensación de su santidad de haber sido escribano el alférez Francisco Pérez de Rojas, padre del dicho don Francisco, en la ciudad de Murcia. En el Consejo, en diez y seis de marzo de 1646 años.

(AHN, Órdenes militares. Santiago. Expedientillo, signatura 2409, doc. n. ${ }^{\circ}$ ).

\section{9. [1646. Resumen del proceso de nombramiento de don Francisco de Ro- jas Zorrilla como caballero de Santiago.]}

El año de 1632 hizo vuestra majestad merced a Alonso Yáñez de Mendoza, difunto, prior de cortes por Guadalajara, de un hábito para don Eugenio Yáñez, su hijo, o para la persona que casase con doña Catalina Yáñez de Mendoza, su hija, como él eligiese; y el secretario Antonio de Alosa ha escrito en primero de este mes de hebrero que Vuestra Majestad pide consulta a la junta de asistentes de cortes, ha resuelto sea de la orden de Santiago y se despache en cabeza del dicho don Francisco de Rojas, por estar casado con la dicha doña Catalina y haber dado 
antes que muriese consentimiento para ello su padre a 8 de abril de 1641 , y despachose el hábito en Madrid, a diez y seis de marzo de 1640 [sic por 1646], insertando la dispensación.

(AHN, Órdenes militares. Santiago. Expedientillo, signatura 2409, doc. n. $\left.{ }^{\circ} 4\right)$.

10. [Diciembre de 1634. Rojas Zorrilla da instrucciones al autor Roque de Figueroa sobre la representación de su comedia Peligrar en los remedios. Autógrafo.]

Señor Roque, reparta v. m. estos papeles como van aquí, porque no ha de ser de otra manera.

Lo primero ha de haber una ventana grande, que sea como de balcón, y llegue hasta el mismo suelo del teatro, y para cuando la abran, haya dentro alguna cosa que no sea ridícula y puesta con buen arte. Lo segundo una puerta verde, con una cerradura sin llave, y por esta no salga nadie en toda la comedia hasta que salga la infanta en la tercera jornada.

\begin{tabular}{|c|c|}
\hline Carlos, infante ...................... & Osuna $^{26}$ \\
\hline Conde Federico, su a & Coca \\
\hline El marqués Alberto, privado ................ & Salazar 27 \\
\hline El rey Sigismundo [de] Nápoles ........ & Juan de la Calle \\
\hline Duque Conrado, padre de Violante.. & Vargas \\
\hline Almirante de Sicilia ................................. & Roque $^{28}$ \\
\hline 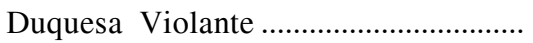 & señora Isabel \\
\hline Infanta de Sicilia & señora María de San Pedr \\
\hline eli & señora Bernarda \\
\hline criado de Violant & Triviño \\
\hline
\end{tabular}

Y si desde aquí al otro año, que es cuando se ha de estrenar, se mudare alguno de la compañía, sea en este mismo grado y adviértase que el rey es muy buen papel, el de Federico y el Marqués Alberto iguales y el de el Almirante casi nada.

(BNE. Vitrina 7-6, f. $33 \mathrm{v}^{\circ}$ ).

11. [1644. Pedro de Covaleda, autor de comedias, escribe al Ayuntamiento de Toledo sobre la representación de una comedia.]

Pedro de Covaleda, autor de comedias por su Majestad, digo que yo quiero servir a V. S. con la Comedia de Tobías, y para ella y otras que tengo de representar se han de hacer algunas apariencias.

A V. S. suplico mande dar licencia para que se hagan como se han hecho con los demás autores, en que recibiré merced.

Pedro de Covaleda [firmado y rubricado].

(Archivo Municipal de Toledo. Cartas, 1640)

${ }^{26}$ Este papel lo hace «Jacinto Va...» en el reparto que antecede a la comedia en el mismo ms., también autógrafo de Rojas.

${ }^{27}$ Este papel lo hace Roque en el reparto que antecede a la comedia en el mismo ms.

${ }^{28}$ Este papel lo hace Paz en el reparto que antecede a la comedia en el mismo ms. 


\section{2. [1645. Memoria de apariencias que Rojas manda a Toledo para que se representen dos autos suyos. Autógrafo.]}

Apariencias del acto de La viña de Nabot, que es el primero que se ha de representar.

- un pescante, en que ha de bajar un ángel.

- un ídolo de pasta o madera, con seis blandones de plata, con seis hachas. Póngase en parte que se pueda hundir.

- dos montañas de verde a los dos lados del teatro que no estorben la fachada. En la una haya un becerro que se pueda hundir; la otra ha de ser una cuesta que pueda rodar por ella una mujer, y hagan las dos montañas iguales para que hermoseen.

- una nube que ha de llover fuego que caiga sobre el ídolo, que se ha de hundir cuando ella le despida.

- otra que después despida agua en forma de lluvia, y sea de manera que no caiga sobre los vestuarios de los representantes el agua, que los manchara los vestidos.

- hase de hacer una viña con treinta cepas y, si no pudieren ser tantas, podrán nivelarla con menos; cada cepa tenga pámpanos que se pueden traer de las viñas, y en una vid que esté en medio, que sea la mayor, haya un cáliz con un pan. Deste cáliz salgan tantas cintas carmesíes de las angostas como hubiere cepas. Si se pudiere hacer esta viña de manera que no parezca la traza a la de los jardines del año pasado, será mejor, porque no se ha de descubrir hasta el fin del auto, y me holgaría que se hiciese alguna novedad. El maestro podrá arbitrar en esto.

- para acabar el auto ha de bajar un carro con dos caballos y un cochero que ha de llevar una figura. Ha de ser de fuego.

Apariencias del acto intitulado Galán, discreto y valiente ${ }^{29}$.

- una valla en que han de tornear cuatro aventureros, que ha de estar suelta, $\mathrm{y}$ un representante la ha de fijar y clavar, que se ha de volver cruz, y en ella ha de subir una figura hasta lo más alto que sea posible.

- de los dos lados de los vestuarios han de salir dos ángeles con dos cipreses y han de subir llevando la cruz en medio; cada ciprés ha de llevar una ángel en una punta.

- hase de hacer un rótulo que diga: INRI en una tabla que tenga cerca de media vara de largo y de ancho ocho dedos.

- ha de haber cuatro palenques por cuatro partes para la entrada de los aventureros.

- una calavera que se ha de poner un representante.

[Acompaña un dibujo que representa lo dicho]

(Archivo Municipal de Toledo. Fondo histórico, caja 881).

${ }^{29}$ Rojas ha tachado la palabra valiente en segundo lugar, que había escrito primero, de tal manera que el título Galán, valiente y discreto se desecha en favor de Galán, discreto $y$ valiente, que se prefiere. 


\section{3. [27 de mayo de 1645. Pedro Ascanio, autor de comedias, se obliga a representar en Toledo los dos autos del Corpus]}

En la ciudad de Toledo, a veinte y siete días del mes de mayor de mil y seiscientos y cuarenta y cinco años, ante mí el escribano pareció presente Pedro de Ascanio, autor de comedias por su Majestad, y se obligó a favor del señor Pedro Fernández de Loaísa y don Gaspar de Cepeda, regidores, y don Francisco de Rivadeneira y don Pedro Sánchez de la Puebla, jurados de Toledo, comisarios de la fiesta del Santísimo Sacramento deste presente año, de hacer y que hará las fiestas representaciones del día del Santísimo Sacramento deste año de cuarenta y cinco en esta manera: que el día del corpus por la tarde en el sitio que es costumbre representar con su compañía dos autos, dos loas, dos entremeses, dos bailes y un sarao y por la mañana en la plaza de Zocodover o en dos sitios donde se le señalare ha de hacer dos representaciones en dichas dos partes y ansimismo el viernes siguiente por la tarde representará los dos autos que ha de representar el jueves en la forma y como se hubiere hecho el día de la fiesta, por razón de lo cual se le dará y pagará de contado por el dicho jurado don Pedro Sánchez de la Puebla como tal comisario siete mil y cuatrocientos reales en moneda de vellón de que el dicho Pedro de Ascanio se dio por contento, por lo que recibe realmente con efeto [...] la entrega, renunció las leyes de casación y dio dello carta de pago en forma.

Y los dichos señores comisarios le han de dar los autos, entremeses y bailes y saraos para estudiarlos. Y si los señores comisarios quisieren que la fiesta que se ha de hacer el viernes siguiente al día del Corpus se haga en otra parte en lugar de la que se había de hacer en el mismo teatro del jueves la ha de hacer la compañía en la parte que ordenaren los señores comisarios. Y la muestra general de los autos se ha de hacer el miércoles víspera del día del Corpus en el Mesón de las comedias, como es costumbre, con todo adorno, sin faltar en cosa alguna. Y en esta conformidad el dicho Pedro Ascanio se obliga a hacer con su compañía la dicha fiesta.

Pedro de Ascanio [firmado y rubricado]

(Archivo Municipal de Toledo. Fondo histórico, caja 881). 
rit.

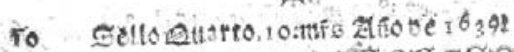

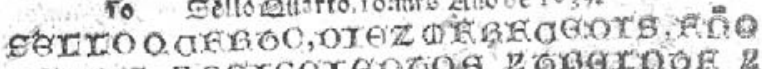

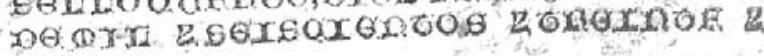
nagas.

$$
\text { Sorro mas }
$$

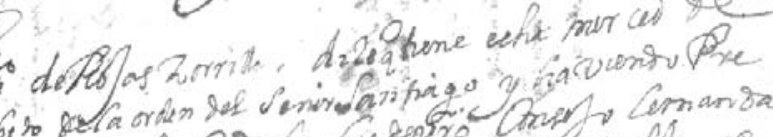

17) $m$

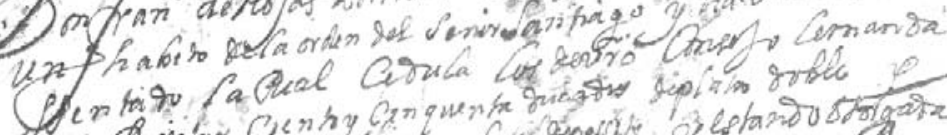

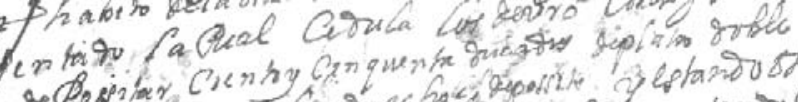

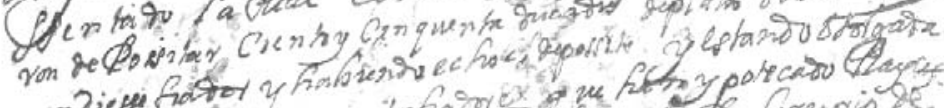

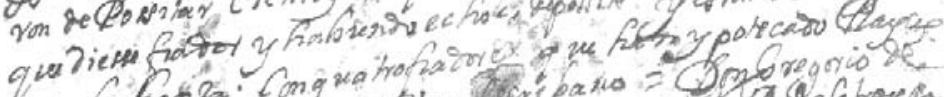

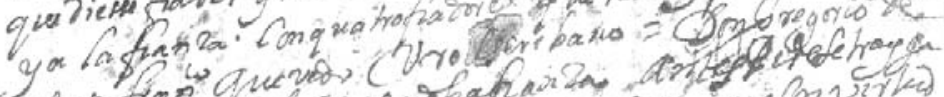

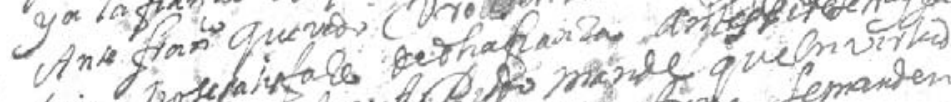

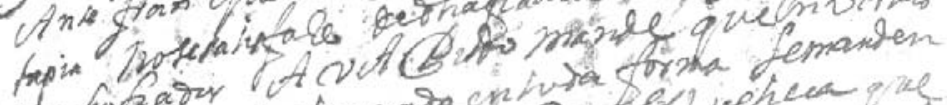

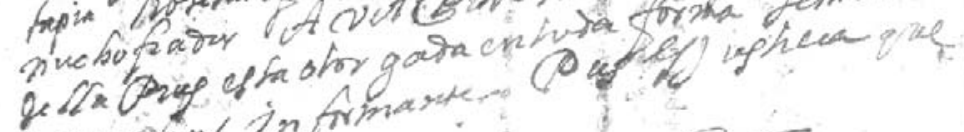

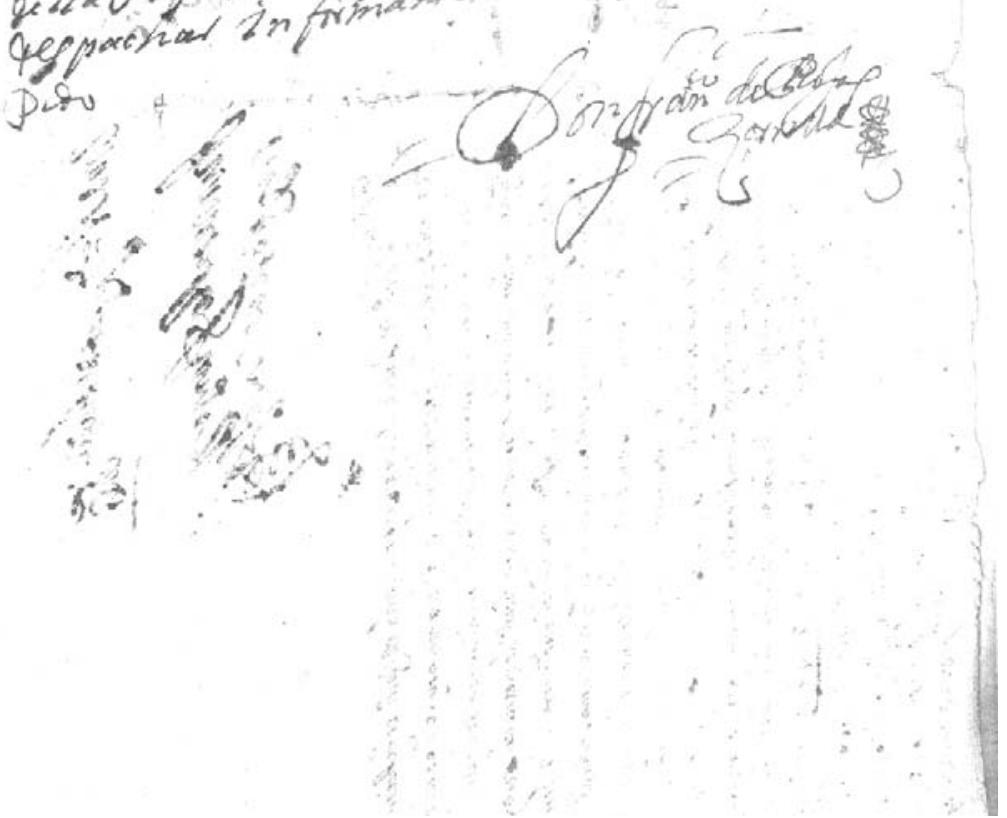

Documento n. ${ }^{\circ} 3$ 


\section{if}
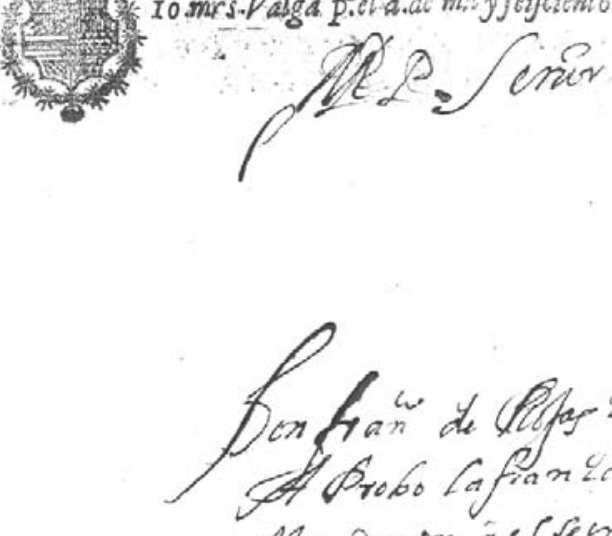

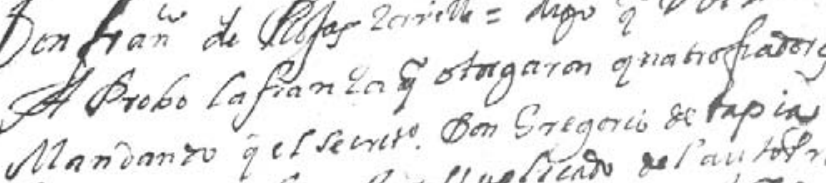

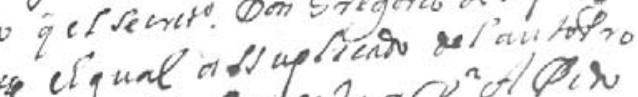

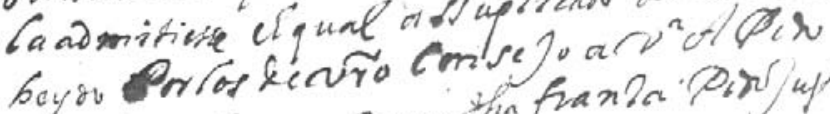

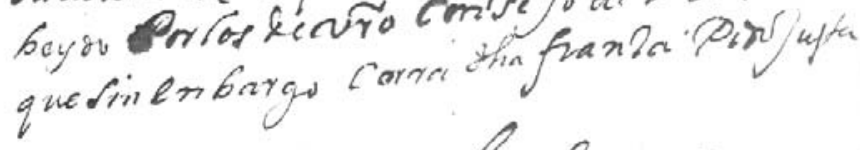

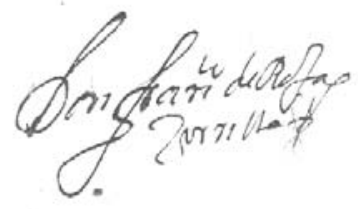

Documento n. ${ }^{\circ} 4$ 


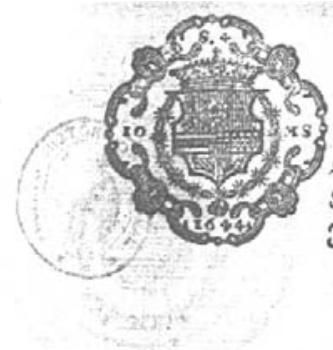

\author{
* \\ Dies marauc ois:
}

SELLOQT

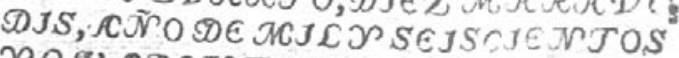

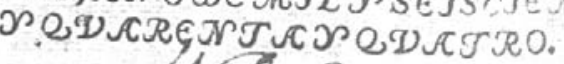

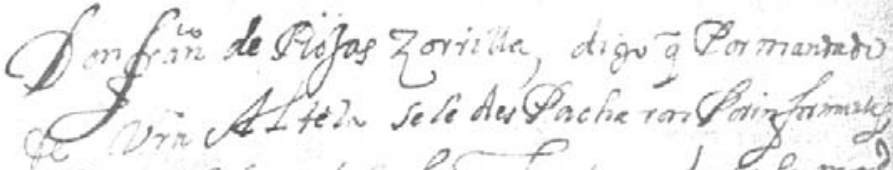

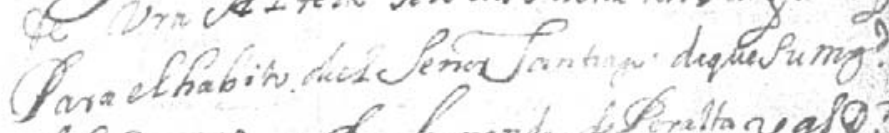

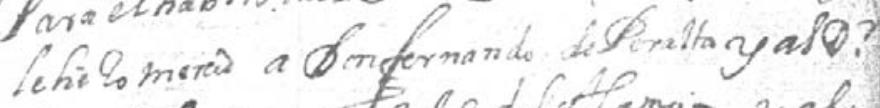

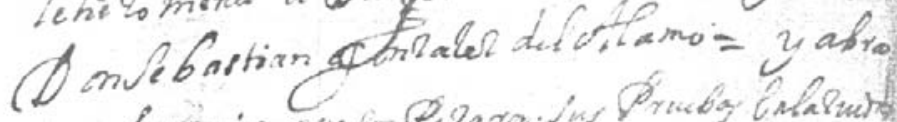

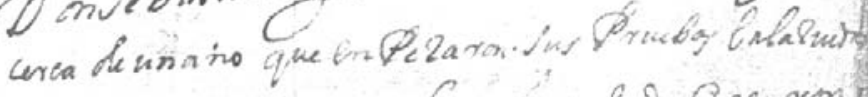

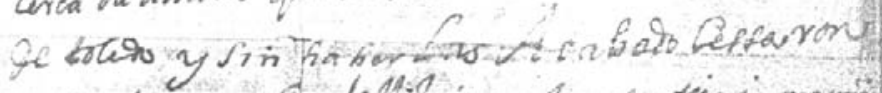

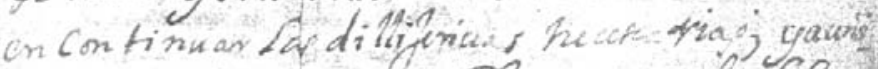

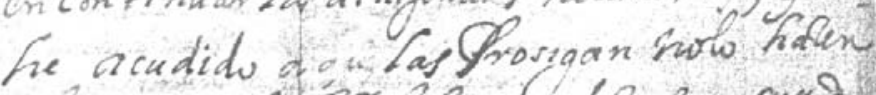

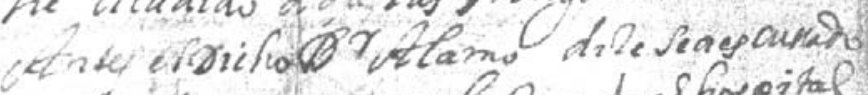

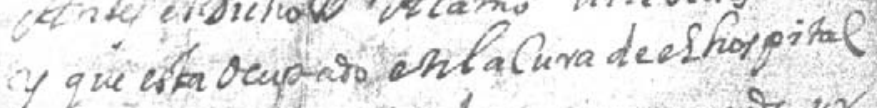
Te donlec arnitistrador y que no pulc $y 2$ a Camontany decfpionora y orra parbion

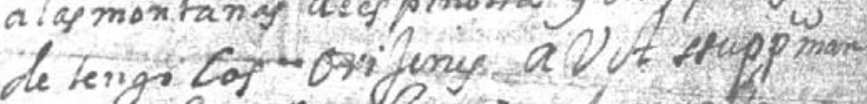

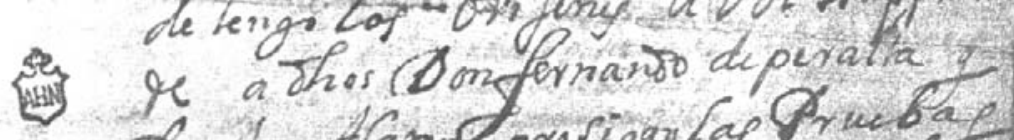

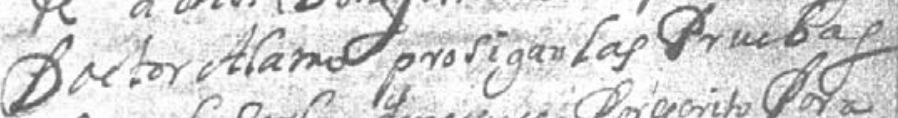

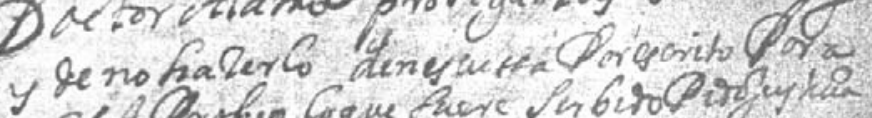

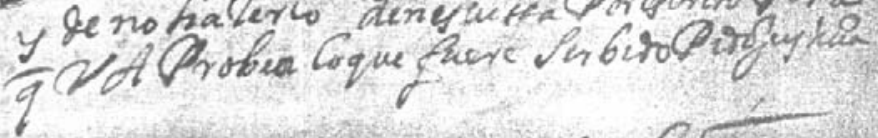
of 


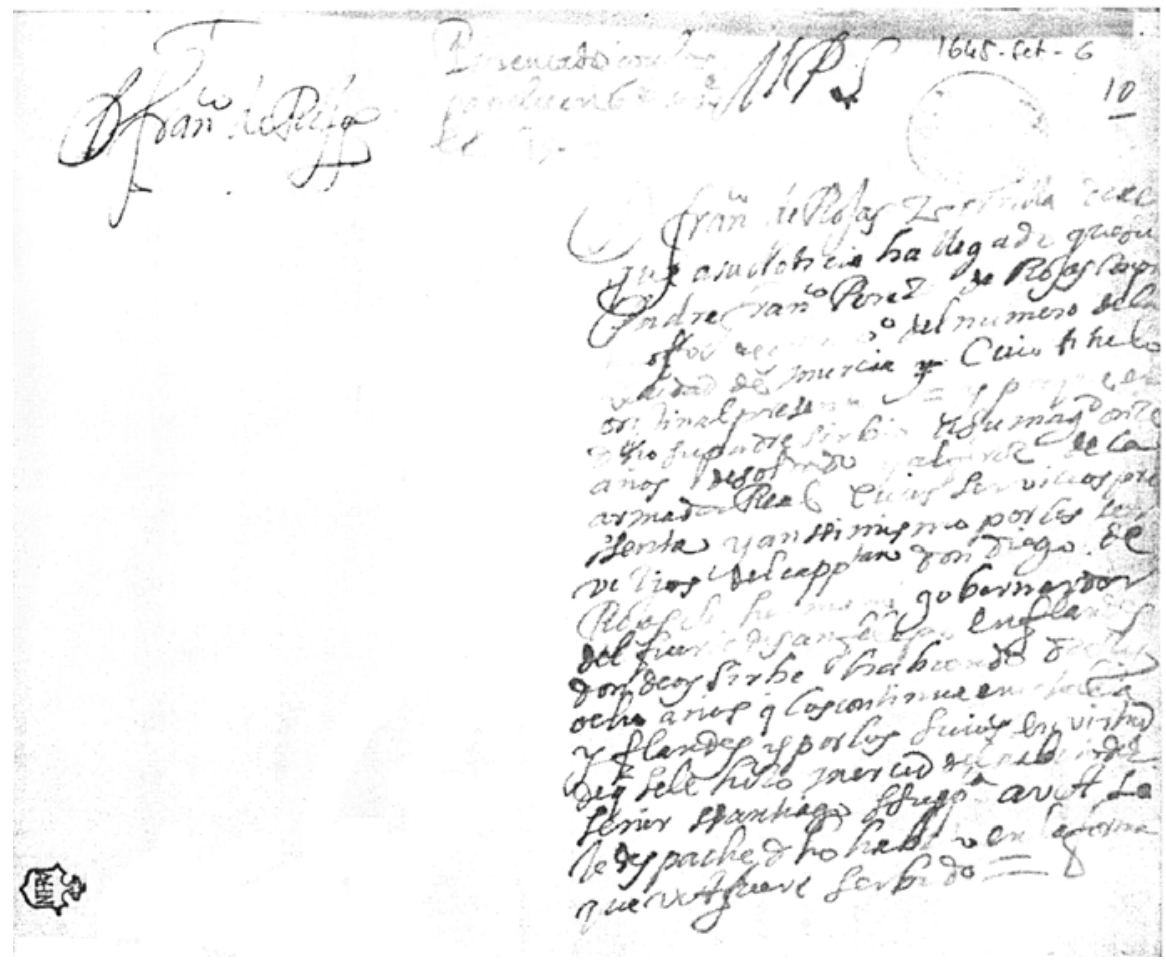

Documento n. ${ }^{\circ} 7$ 
F

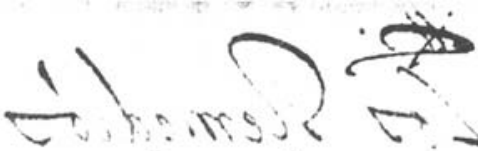

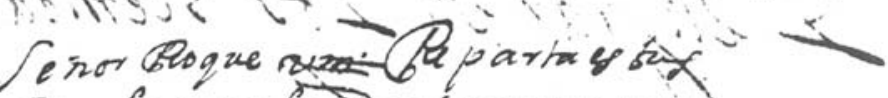
Capeles como bañamiporque nul

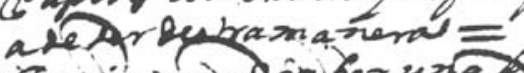

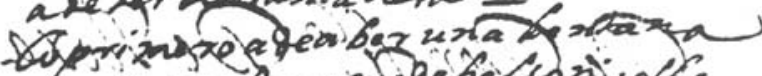

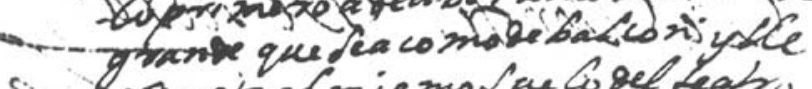

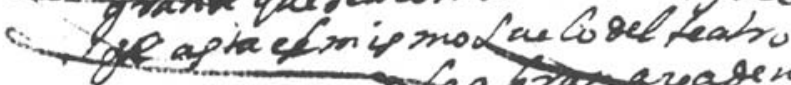
y paraquan robar binumasento

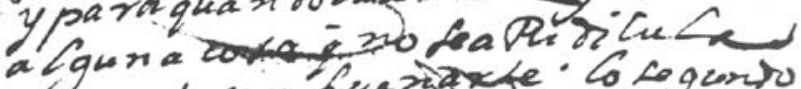

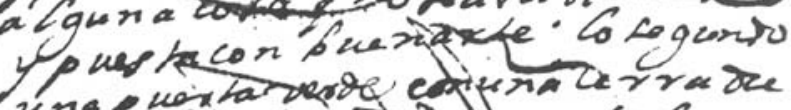

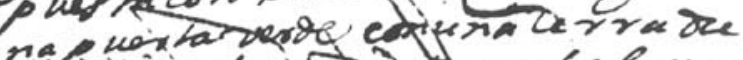

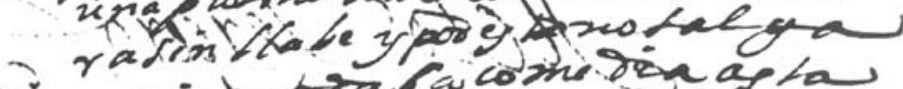

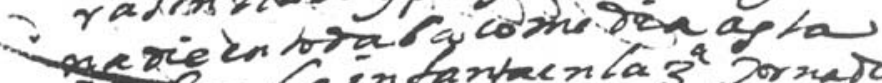

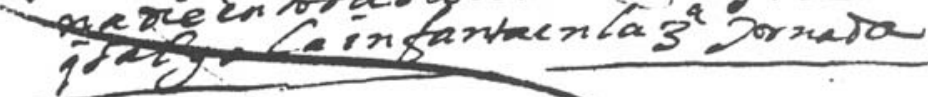

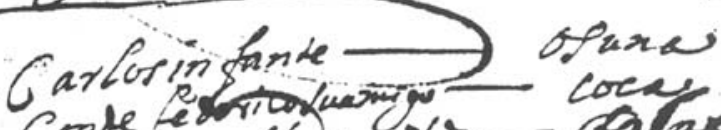

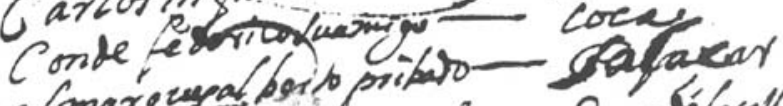

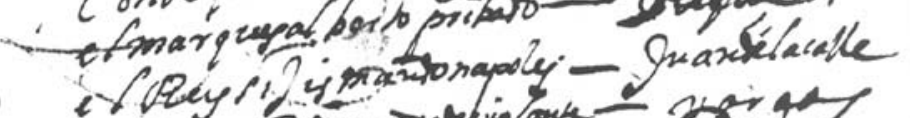

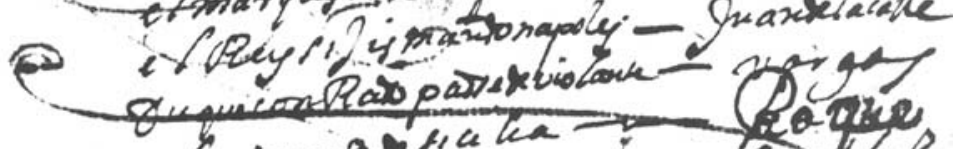

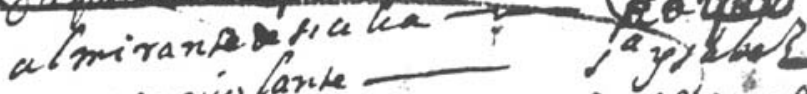
Tuques a wiw larke.

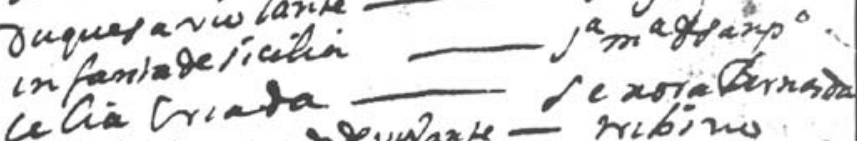

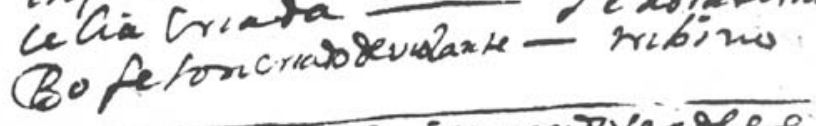

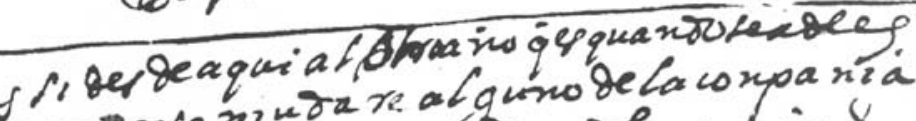

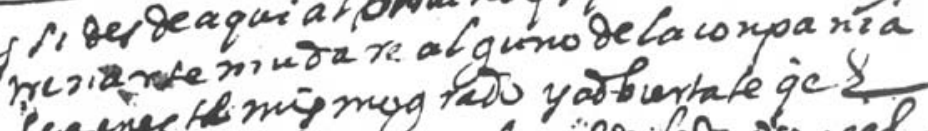

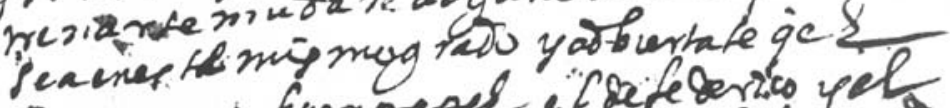

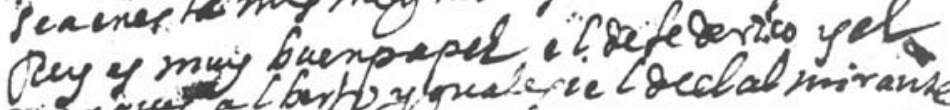

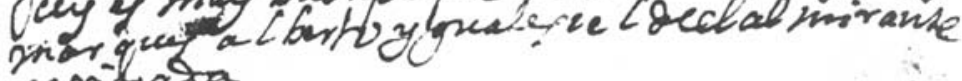
carritiata 


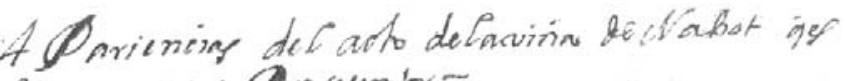

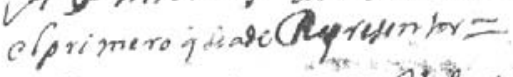

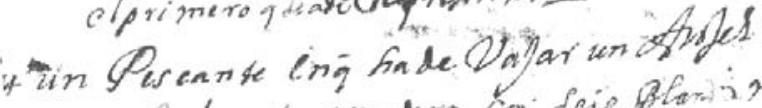

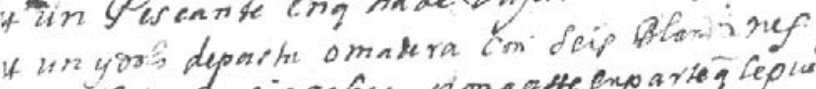

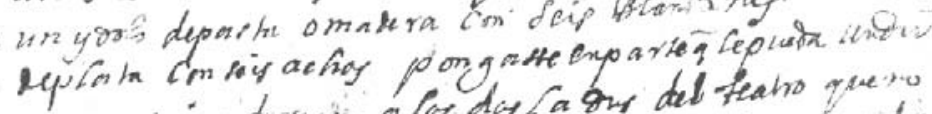

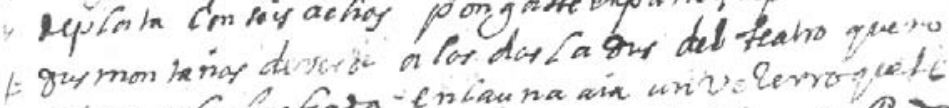

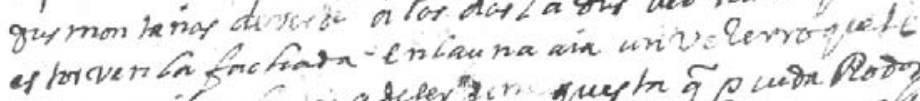

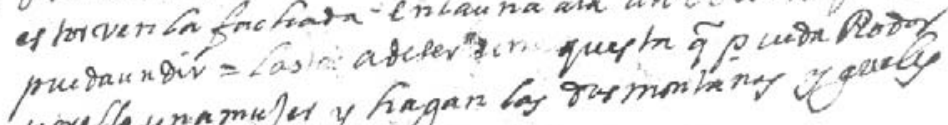

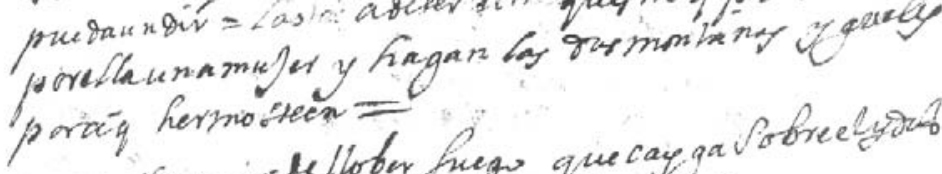

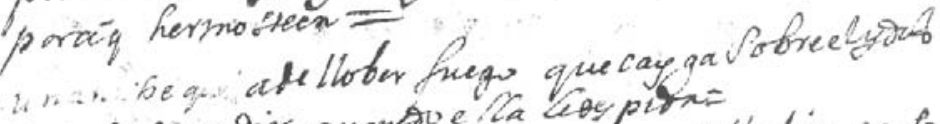

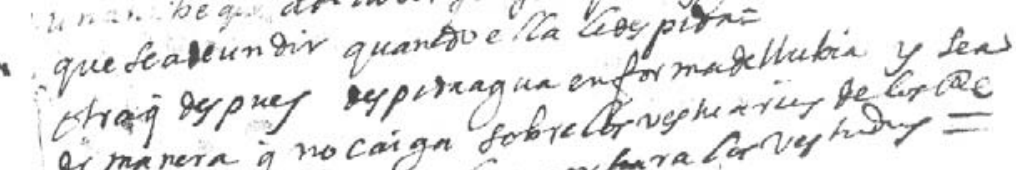

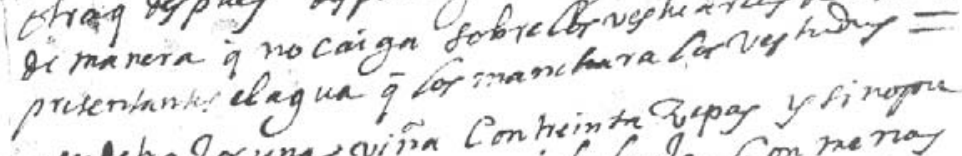

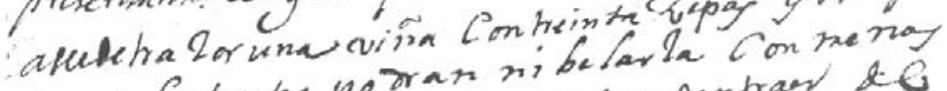

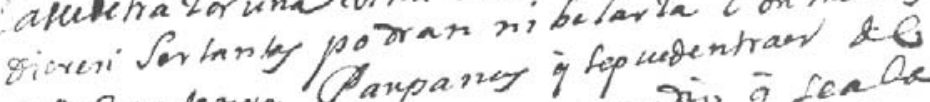

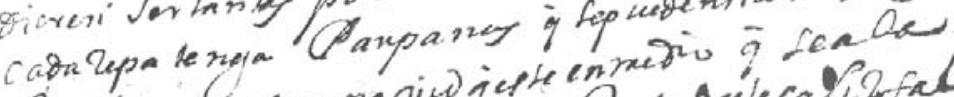

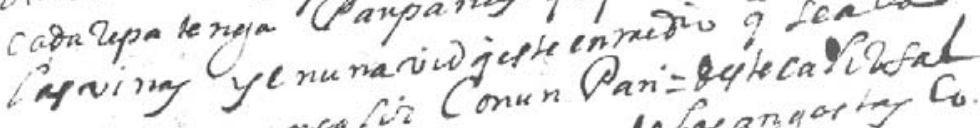

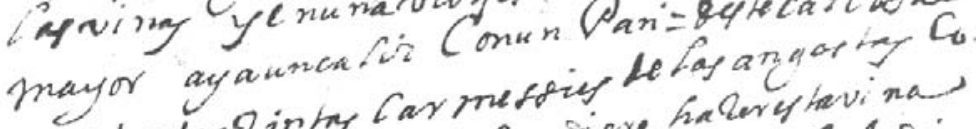

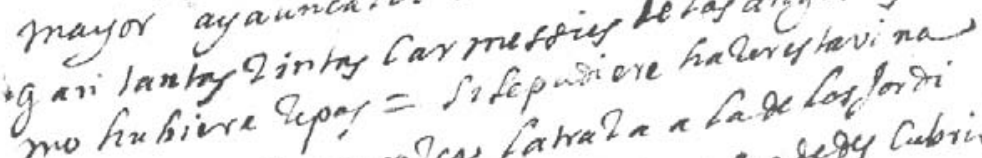

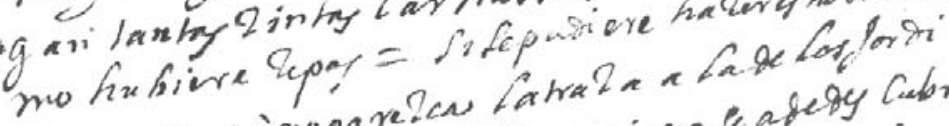

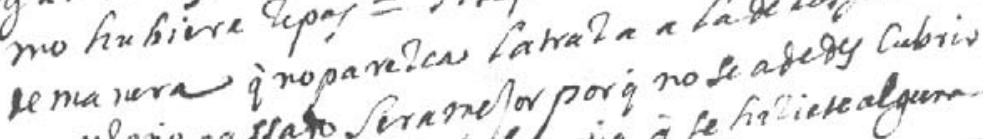

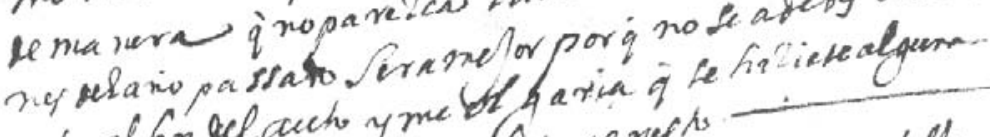

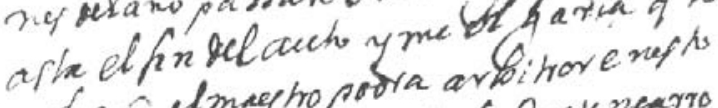

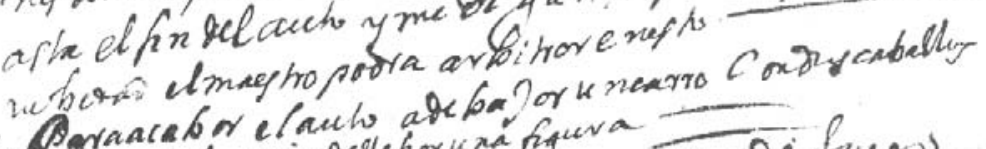

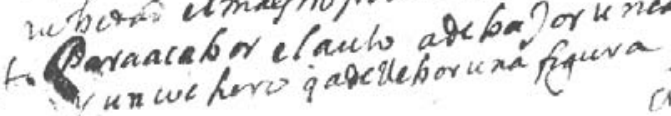

ace Difugo 
2. Wna valikenqui ande torneas quatro abon hurerey que aleytar Sueltay un Pepre fentank iaabfition yelabor quetex we bot bor Crah ye nella ate rk bir una

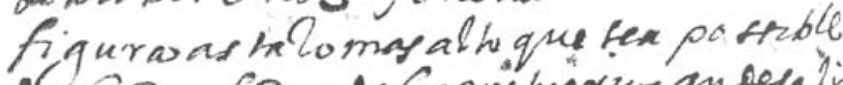

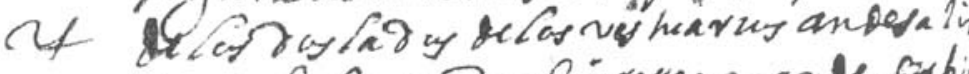

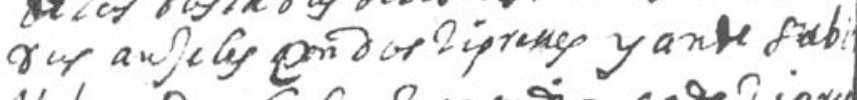

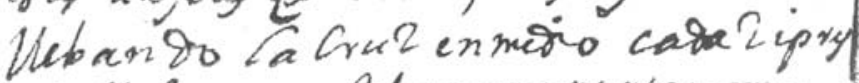
a pellebrarunapel enkpepuxa -

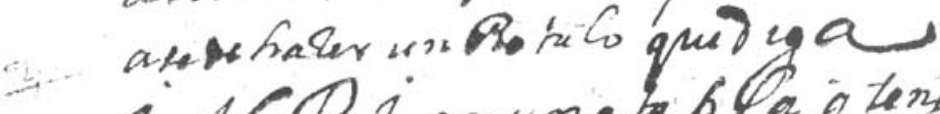

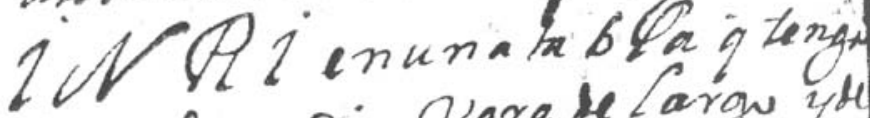
Cerca demetio Nara Le argu zh anchio of hu betas

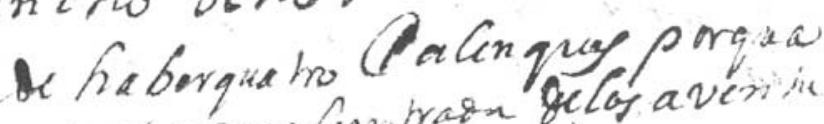
hopark parafartrain gelog avenis riroy $=$

in a Calabera = qeendeponesun Representems.

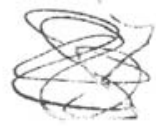




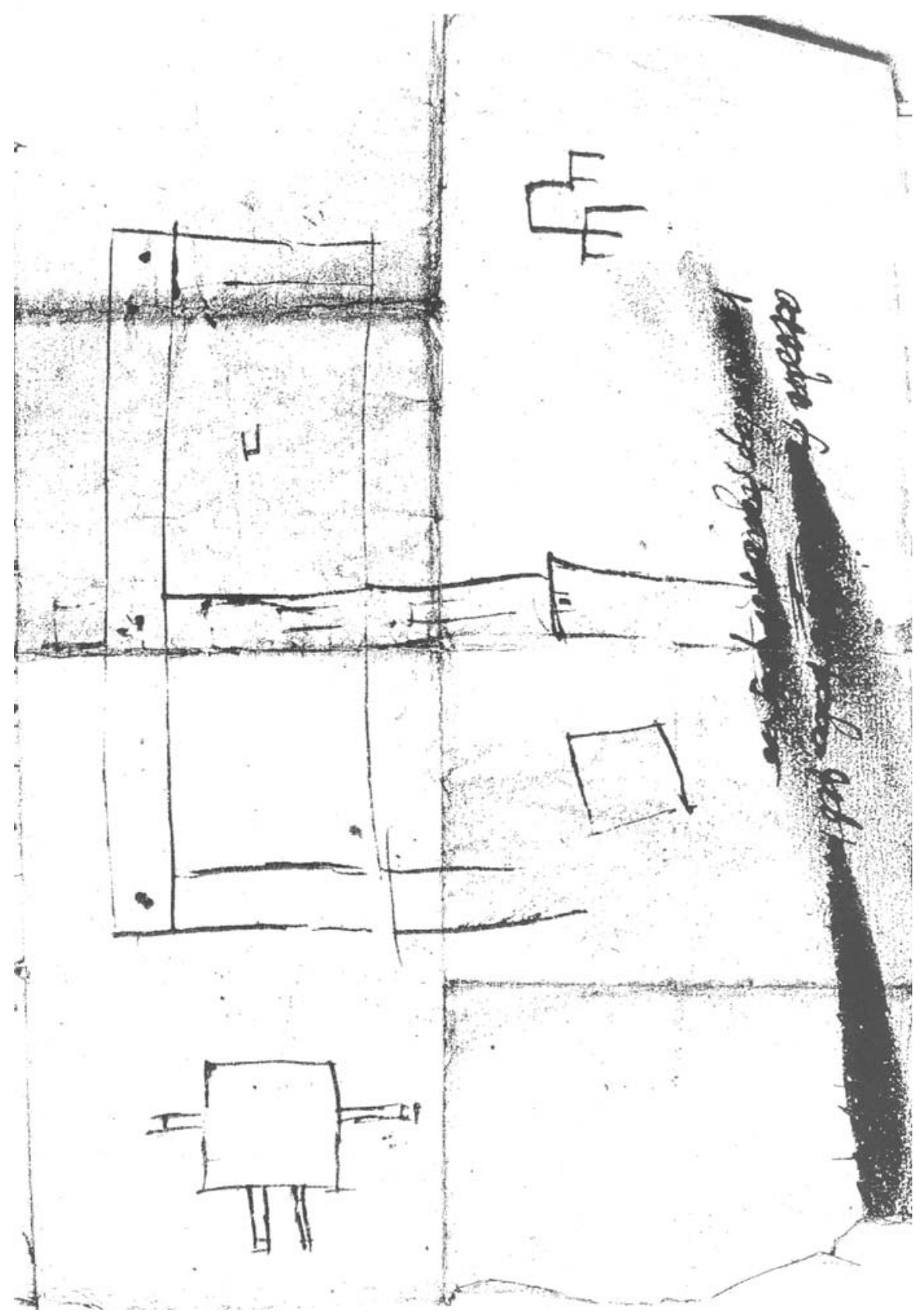

Documento n. ${ }^{\circ} 12$, f. 2 r $^{\circ}$ 